This item was submitted to Loughborough's Research Repository by the author.

Items in Figshare are protected by copyright, with all rights reserved, unless otherwise indicated.

\title{
The aerodynamic drag of a compact SUV as measured on-road and in the
} wind tunnel

PLEASE CITE THE PUBLISHED VERSION

http://dx.doi.org/10.4271/2002-01-0529

PUBLISHER

SAE International

VERSION

VoR (Version of Record)

LICENCE

CC BY-NC-ND 4.0

REPOSITORY RECORD

Howell, Jeff, Chris Sherwin, Martin A. Passmore, and G.M. Le Good. 2010. "The Aerodynamic Drag of a Compact SUV as Measured On-road and in the Wind Tunnel”. figshare. https://hdl.handle.net/2134/6709. 


\section{Aerodynamic Drag of a Compact SUV as Measured On-Road and in the Wind Tunnel}

Jeff Howell and Chris Sherwin

Land Rover

Martin Passmore

Loughborough University

Geoff Le Good

Bentley Motors

Reprinted From: Vehicle Aerodynamics Studies

(SP-1667) 
The appearance of this ISSN code at the bottom of this page indicates SAE's consent that copies of the paper may be made for personal or internal use of specific clients. This consent is given on the condition, however, that the copier pay a per article copy fee through the Copyright Clearance Center, Inc. Operations Center, 222 Rosewood Drive, Danvers, MA 01923 for copying beyond that permitted by Sections 107 or 108 of the U.S. Copyright Law. This consent does not extend to other kinds of copying such as copying for general distribution, for advertising or promotional purposes, for creating new collective works, or for resale.

Quantity reprint rates can be obtained from the Customer Sales and Satisfaction Department.

To request permission to reprint a technical paper or permission to use copyrighted SAE publications in other works, contact the SAE Publications Group.

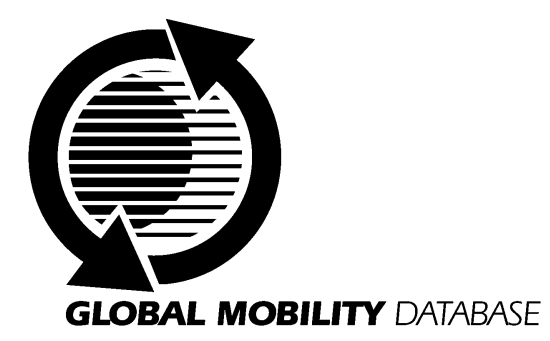

All SAE papers, standards, and selected books are abstracted and indexed in the Global Mobility Database

No part of this publication may be reproduced in any form, in an electronic retrieval system or otherwise, without the prior written permission of the publisher.

\section{ISSN 0148-7191}

Copyright 2002 Society of Automotive Engineers, Inc.

Positions and opinions advanced in this paper are those of the author(s) and not necessarily those of SAE. The author is solely responsible for the content of the paper. A process is available by which discussions will be printed with the paper if it is published in SAE Transactions. For permission to publish this paper in full or in part, contact the SAE Publications Group.

Persons wishing to submit papers to be considered for presentation or publication through SAE should send the manuscript or a 300 word abstract of a proposed manuscript to: Secretary, Engineering Meetings Board, SAE.

\section{Printed in USA}




\title{
Aerodynamic Drag of a Compact SUV as Measured On-Road and in the Wind Tunnel
}

\author{
Jeff Howell and Chris Sherwin \\ Land Rover \\ Martin Passmore \\ Loughborough University \\ Geoff Le Good \\ Bentley Motors
}

Copyright @ 2002 Society of Automotive Engineers, Inc.

\begin{abstract}
Growing concerns about the environmental impact of road vehicles will lead to a reduction in the aerodynamic drag for all passenger cars. This includes Sport Utility Vehicles (SUVs) and light trucks which have relatively high drag coefficients and large frontal area. The wind tunnel remains the tool of choice for the vehicle aerodynamicist, but it is important that the benefits obtained in the wind tunnel reflect improvements to the vehicle on the road. Coastdown measurements obtained using a Land Rover Freelander, in various configurations, have been made to determine aerodynamic drag and these have been compared with wind tunnel data for the same vehicle. Repeatability of the coastdown data, the effects of drag variation near to zero yaw and asymmetry in the drag-yaw data on the results from coastdown testing are assessed. Alternative blockage corrections for the wind tunnel measurements are examined. A reasonable correlation between wind tunnel and on-road aerodynamic drag data is established for the configurations tested.
\end{abstract}

\section{INTRODUCTION}

Automotive manufacturers have achieved a significant reduction in the aerodynamic drag of passenger cars over the last twenty years. This has been done largely through the optimisation of upper body shape and refinement of the vehicle underside. Although this trend on passenger cars has slowed during the last few years it has been only recently that a similar effort has been applied to SUVs and larger $4 \times 4 \mathrm{~s}$. A continued reduction in the aerodynamic drag of these vehicles will be necessary if they are to meet the increasingly stringent exhaust emission targets that are being set by almost all developed nations and the fuel economy expectations of most customers. This applies in particular for carbon dioxide output which is seen as a major contributor to the problem of global warming.

Carbon dioxide output is directly related to fuel consumption. As the drive cycle over which fuel economy is measured predominantly simulates urban usage aerodynamic drag reduction appears to have less influence than powertrain efficiency or weight reduction for improving fuel consumption. Aerodynamic drag remains an important element in vehicle design, however, because reduction is achievable at relatively low cost. Fuel consumption is determined from vehicles which are run on a dynamometer where the resistance values have been generated from road load data. The vehicle aerodynamicist must, therefore, ensure that any drag reductions can be realistically achieved on the road and not just in the wind tunnel.

It is traditional for vehicle aerodynamic drag development to be carried out in a wind tunnel, which provides a controlled and repeatable environment for testing. In a conventional full-scale aerodynamic wind tunnel test the true boundary conditions at the ground surface are not satisfied. The boundary layer, which develops on a fixed floor, is unrepresentative of ground conditions experienced on the road. In addition the wheels do not rotate influencing airflow through the wheel arches, and the aerodynamic energy losses due to wheel rotation are not determined, Le Good (1).

Improved simulation of road conditions was initially attempted in many full-scale automotive wind tunnels by incorporating systems that would reduce the ground plane boundary layer. Some full-scale wind tunnels have 
installed moving ground and rotating wheel systems. A wide belt was installed in the floor of the DNW wind tunnel (2) and demonstrated the need for better simulation, but the requirement to modify the test vehicle so that it could be mounted on a tail sting was a costly limitation. Pininfarina (3) subsequently pioneered the narrow belt technique where a belt is installed in the turntable and operates between the wheels of the test car. Rotation of the wheels is generated by mounting them on small rollers outboard of the belt. Similar installations are now operational in both Audi and IVK wind tunnels.

As these advanced techniques are not universally available to the automotive aerodynamicist there remains a need to understand the limitations of conventional wind tunnel testing with a fixed floor, and to ensure that the partial simulation of the true boundary conditions afforded by the narrow belt system is realistic. The only way this can be done is to measure the aerodynamic drag in the real world, ie on the road, and to compare it with wind tunnel data. Buckley (4), Le Good et al (5), and Walter et al (6) have used advanced coastdown techniques to derive aerodynamic drag data from 'on road' testing. The technique appears to have sufficient resolution and repeatability to enable correlation between wind tunnel and track derived data.

All the coastdown testing referenced above concerned passenger cars and there is only limited published data on other road vehicles. Earlier exceptions are the coastdown tests carried out on full size trucks by Buckley (7) and on a $4 \times 4$ by Eaker (8). At Land Rover, as a manufacturer of off-road vehicles, it was felt that there was a need to perform similar tests on an SUV. Coastdown tests were therefore carried out on the Freelander compact SUV, in various configurations, and the drag data derived on-road compared with results obtained from the MIRA Full Scale Wind Tunnel. This facility was used in the aerodynamic development of Freelander.

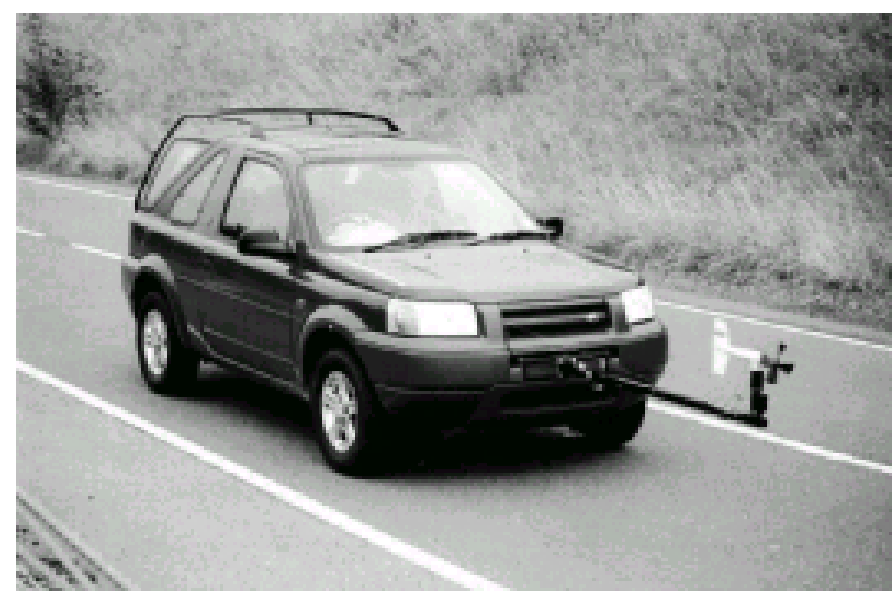

Figure 1. Land Rover Freelander during coastdown testing.

\section{TEST VEHICLE AND CONFIGURATIONS}

The test vehicle used in this investigation was a preproduction 3 door Land Rover Freelander, in European specification, as shown in Figure 1. Freelander was launched in Europe in 1997 and was Land Rover's first vehicle in the compact SUV class. It was available in 3 and 5 door versions and initially the engines were either a 1.8 litre petrol, as the test vehicle, or 2.0 litre diesel. Recently a 2.5 litre V6 has been introduced, and the vehicle is now available in this configuration in the U.S.A. All derivatives now have a slightly extended front bumper, designed to accommodate the V6 installation. The principal dimensions of the test vehicle are listed below:

\section{Vehicle General data:}

$\begin{aligned} \text { Overall length } & =4382 \mathrm{~mm} \\ \text { Overall width } & =2068 \mathrm{~mm} \\ \text { Overall height } & =1828 \mathrm{~mm} \\ \text { Wheelbase } & =2557 \mathrm{~mm} \\ \text { Track (front) } & =1534 \mathrm{~mm} \\ \text { Track (rear) } & =1545 \mathrm{~mm} \\ \text { Frontal Area } & =2.55 \mathrm{~m}^{2} \\ \text { Wheels/Tyres } & =195 / 80 \mathrm{R} 15 \mathrm{5} \text { spoke alloys }\end{aligned}$

The baseline configuration for these tests had the standard 3-door 'Hard top' fitted. In this configuration two further modifications were tested; first, large triangular section spoilers were added to the rear pillars, and second, vertical strakes were mounted to the outer edges of the bonnet and extending from the A-pillars to the bonnet leading edge. For configuration 4 the 'Hard top' was removed providing a vehicle in 'Open top' mode and for the configuration 5 the standard 'Soft top' was fitted. Throughout all tests the standard roof rails and cross bar arrangement was fitted and the spare wheel remained mounted to the tailgate. All the configurations tested are shown in Figure 2.

The basic aerodynamic characteristics at zero yaw are given in Table 1 for the baseline configuration set up to the EADE test standard (ie 3-up), and as tested with two occupants, test equipment, and the boom with anemometer mounted to the front bumper. Fitting the boom and anemometer alone to the front of the test vehicle increased the drag coefficient by 0.006 . A small reduction in drag coefficient $\left(\Delta C_{D}=0.001\right)$ was noted for the small change of attitude.

\begin{tabular}{|c|c|c|c|}
\hline $\begin{array}{c}\text { Vehicle Test } \\
\text { Configuration }\end{array}$ & $\mathbf{C}_{\mathbf{D}}$ & $\mathbf{C}_{\mathrm{LF}}$ & $\mathbf{C}_{\mathrm{LR}}$ \\
\hline EADE & 0.401 & 0.090 & 0.045 \\
\hline As Coastdown & 0.406 & 0.080 & 0.045 \\
\hline
\end{tabular}

Table 1. Basic Aerodynamic Characteristics. Zero Yaw. 


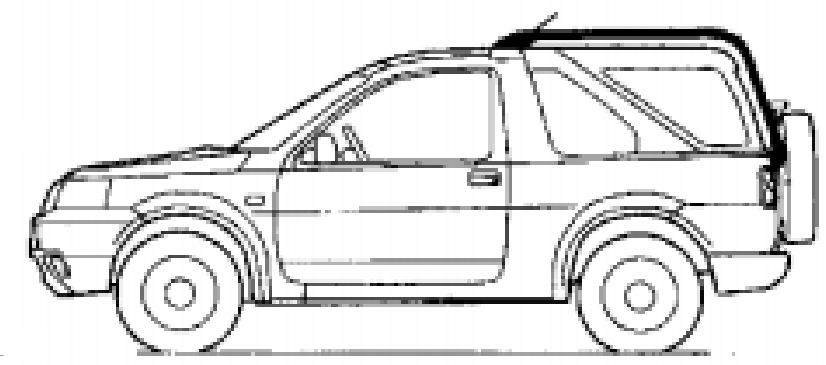

Config. 1 Baseline 3door with Hard Top

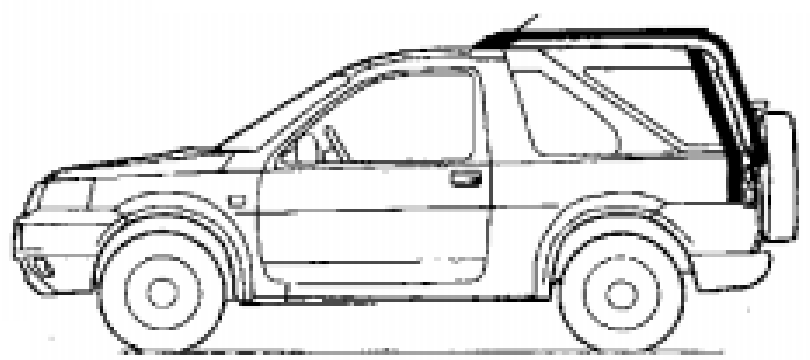

Config. 2 Base + Rear Pillar Spoilers

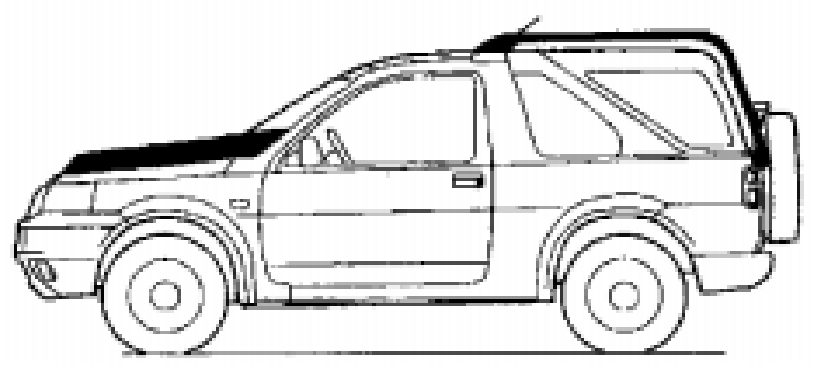

Config. 3 Base + Bonnet Strakes

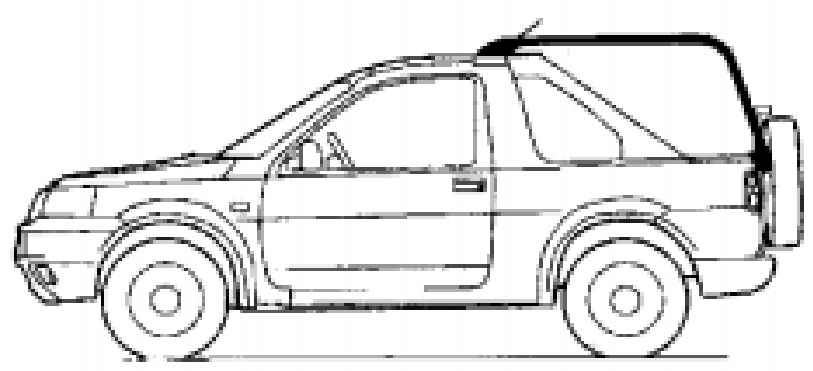

Config. 4 Base + Hard Top removed

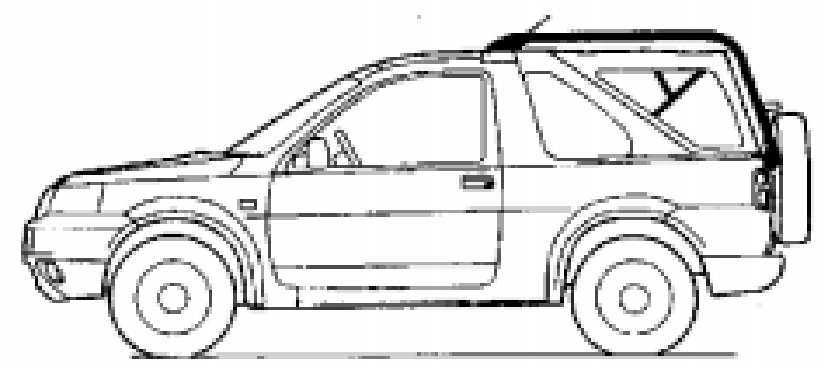

Config. 5 Config. $4+$ Soft Top

\section{WIND TUNNEL TESTING}

Wind tunnel tests were conducted in the MIRA full-scale wind tunnel. This facility has a closed working section and open return. The tunnel has a working section which is $15.2 \mathrm{~m}$ long and the cross-sectional area is $34.9 \mathrm{~m}^{2}$. For the Freelander test vehicle which has a frontal area of $2.55 \mathrm{~m}^{2}$ the solid blockage is $7.3 \%$.

The wheels of the test vehicle are positioned on small rectangular pads, $0.25 \mathrm{~m}$ square, which are adjustable for track and wheelbase, and are flush with the tunnel floor. The plates are connected to a six-component underfloor balance. The nominal wind tunnel test speed is $27 \mathrm{~m} / \mathrm{s}(100 \mathrm{k} / \mathrm{h})$.

No boundary layer control system is employed in the standard vehicle test procedure at the MIRA wind tunnel, the displacement thickness being $17 \mathrm{~mm}$ on the tunnel floor at the balance. All the measured data is corrected for blockage and horizontal buoyancy. See Results section.

In the wind tunnel the vehicle is restrained using the transmission, hand brake and foot-brake, and was ballasted to achieve the same static ride height conditions as measured for the coastdown tests.

For all configurations tested in the wind tunnel the boom and anemometer, standard roof bars and cross rail arrangement were fitted, and the spare wheel remained mounted to the tailgate. The overall effect of fitting the boom and anemometer to the vehicle was to increase the drag coefficient by 0.006 .

The drag data as measured in the wind tunnel is presented in Figure 3 for each configuration as a function of yaw angle. Zero yaw drag is given below in Table 2 for the five configurations. Most configurations demonstrate an approximate symmetry about the zero yaw axis, except for the open back configuration, where a marked asymmetry exists. The reasons for this are not understood but may be associated with the exposure of the tailgate mounted spare wheel, which is positioned off-centre. The effect of symmetry or otherwise on the coastdown data is discussed later.

\begin{tabular}{|c|c|c|}
\hline Configuration & $\mathrm{C}_{\mathrm{D}} 0^{\circ}$ yaw & $\Delta \mathrm{C}_{\mathrm{D}}-5^{\circ}$ to $+5^{\circ}$ \\
\hline 1 & 0.406 & -0.004 \\
\hline 2 & 0.494 & -0.007 \\
\hline 3 & 0.427 & -0.002 \\
\hline 4 & 0.431 & -0.018 \\
\hline 5 & 0.418 & +0.001 \\
\hline
\end{tabular}

Figure 2. Vehicle configurations for coastdown tests.

Table 2. Drag Coefficients. Wind Tunnel Data. 


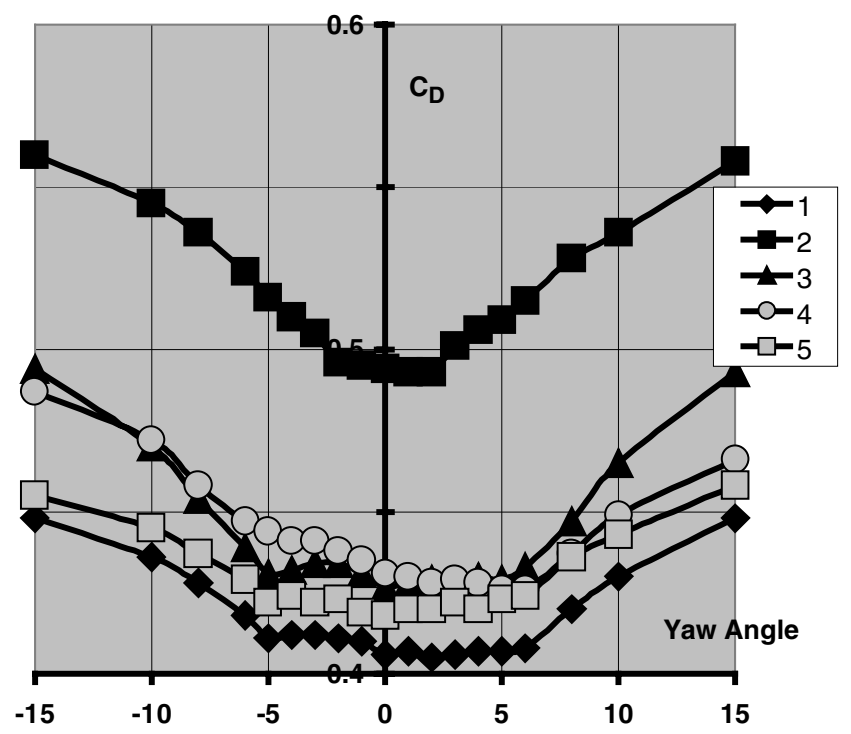

Figure 3. Drag Coefficient as a function of Yaw Angle.

\section{BACKGROUND TO COASTDOWN METHOD}

The coastdown method is an established technique of determining the components of drag acting on a vehicle in its normal operating environment. The test consists of accelerating the vehicle up to the maximum speed of interest, shifting into neutral and allowing the vehicle to freely decelerate. The technique used here is an advanced coastdown technique employing on-board anemometers to continuously measure the ambient conditions. This allows the accurate separation of the contributions to the drag.

The equation of motion for a vehicle travelling in a straight line is a straightforward application of Newton's second law.

$$
F_{T}=F_{D}(v)+M_{e} \frac{d v}{d t}+M g \sin \alpha
$$

$$
\begin{aligned}
& \text { Tractive } \\
& \text { Effort }
\end{aligned} \underset{\text { Force }}{\text { Resistive }}+\underset{\text { Force }}{\text { Inertial }}+\underset{\text { Force }}{\text { Gravitational }}
$$

During the coastdown test the tractive effort is zero, as the vehicle is in neutral, and when possible the tests are conducted on a level track (i.e. $\alpha=0$ ), so the gravitational term is zero. The resistive force is therefore proportional to the acceleration. The inertia $\left(\mathrm{M}_{\mathrm{e}}\right)$ includes an allowance for those components rotating during the coastdown as well as the basic vehicle mass. This includes the wheels, half shafts and part of the final drive and gearbox, though in practice only the inertia of the wheels makes a significant contribution. Defining the form of the resistive force function presents one of the main difficulties in correctly analysing the coastdown data and different models may be applied for different vehicle types. The model used for this analysis is given in equation 2.

$$
\begin{aligned}
F_{D}(v)= & M g\left(\boldsymbol{A}_{\boldsymbol{d}}+\boldsymbol{B}_{\boldsymbol{d}} v\right)\left[1+K_{T}\left(T_{o}-T_{s}\right)\right] \\
& +\frac{1}{2} \rho A \boldsymbol{C}_{D}(\psi) v_{r}^{2}+F_{M}\left(v, T_{o i l}\right)
\end{aligned}
$$

\section{Total $=$ Tyres + Aerodynamics + Mechanical}

The unknowns shown in bold typeface are determined during the analysis of the coastdown data. The form taken by the aerodynamic drag function $C_{D}(\psi)$ is given by equation 3 .

$$
C_{D}(\psi)=C_{D_{0}}+K_{d} \psi^{2}
$$

Equation 2 also shows that for a full and accurate analysis of the coastdown it is necessary to continuously measure vehicle speed, airspeed and yaw angle.

The mechanical term $F_{M}\left(v, T_{\text {oil }}\right)$ represents the losses associated with the driveline and un-driven wheels and these were measured separately in an experiment in the laboratory.

A detailed description of the coastdown method and the analysis of the acquired data is given in (9).

THE COASTDOWN TESTS - The tests were conducted on the Twin Horizontal Straights at the MIRA Proving Ground, in the UK. The tracks are one mile long and level. The following test procedure was carried out to ensure maximum repeatability.

Prior to all tests, the vehicle was weighed, the tyre pressures were set to the equivalent of $1.93 \mathrm{bar}$ at $20^{\circ} \mathrm{C}$ and the vehicle static trim heights were measured. From cold, the vehicle was run on the test track at a steady speed of $22 \mathrm{~m} / \mathrm{s}(80 \mathrm{~km} / \mathrm{h})$ for approximately 20 minutes to condition the tyres and oil temperature.

At a starting speed of approximately $120 \mathrm{~km} / \mathrm{h}$ each coastdown run typically took $70-80$ seconds to complete. By the end of each test run the vehicle speed had reduced to between $20 \mathrm{~km} / \mathrm{h}$ and $40 \mathrm{~km} / \mathrm{h}$. 20 test runs (10 in each direction) were carried out for each aerodynamic configuration. The runs were grouped together in pairs (i.e. 1 in each direction) for the purpose of anemometer calibration.

At the end of each series of tests the static trim heights were re-measured, to ensure vehicle consistency. Also the vehicle was re-weighed for use in the analysis. A linear reduction of weight (due to fuel usage) with distance travelled was assumed. Dynamic trim heights were not measured. 
INSTRUMENTATION - For the track tests, the vehicle was instrumented to measure road speed, airspeed and yaw angle. This instrumentation was also fitted throughout the wind tunnel tests to ensure that the aerodynamic configurations were identical in each test method.

Airspeed and aerodynamic yaw angle measurements were made by means of a combined propeller and vane anemometer mounted on a boom extending $1.5 \mathrm{~m}$ from the front of the vehicle, as shown in Figure 1. The anemometer centreline was positioned at the vehicle mid-height, as recommended in SAE J2263 (10). Three adjustable stays from the vehicle front end minimise boom movement during the coastdown tests. The vehicle speed was measured using the antilock wheel speed sensors.

Using an onboard computer, with proprietary data acquisition software, continuous measurements of airspeed, yaw angle and vehicle speed were sampled throughout the deceleration phase of the test. Prior to sampling, (at $5 \mathrm{~Hz}$ ), the data was filtered using a $0.8 \mathrm{~Hz}$ corner frequency low pass anti-aliusing filter. The transmission oil temperature was also recorded during the test phase and was obtained from a thermocouple fitted via the sump drain plug. This allowed an accurate correction to be made for the driveline losses, based on laboratory measurements.

DRIVELINE LOSS MEASUREMENT - The drive-line losses were determined in the laboratory by performing a coastdown on the drivetrain alone, while supporting the vehicle with the wheels clear of the ground and the suspension configured to reproduce the on road trim heights. The road wheels are replaced with bolt-on steel flywheels; $0.7 \mathrm{~m}$ diameter and $13 \mathrm{~mm}$ thick. These provide a relatively large, known, inertia and reduce the aerodynamic component that would arise from using road wheels (1). The coastdown is conducted from an appropriate upper speed, and the wheel angular speed and driveline temperature monitored. The test is then repeated a number of times to acquire data over the range of oil temperatures encountered during the trackbased coastdowns. For the $4 \times 4$ vehicle used here the downhill descent control feature was disabled and the speed of all four wheels measured. There was negligible difference, however, between the speed of the wheels during the coasting phase.

The data is analysed by averaging the four wheel speeds and differentiating to yield torque against angular speed using the known inertias, and thereby drag as a function of vehicle speed. A regression of all the data over the range of driveline temperatures is then performed to determine the coefficients and temperature correction factor in the driveline model.

$F_{M}(v)=\left[A_{t}+B_{t} v+C_{t} v^{2}+D_{t} v^{3}\right] e^{-k T_{o i l}}$
COASTDOWN ANALYSIS - The coefficients in the coastdown equation described are determined by fitting the mathematical model to the measured speed data using an optimisation routine to minimise the cost function (sum of errors squared) $F(\mathbf{x})$, where $\mathbf{x}$ is the estimate of the coefficients. The cost is calculated by integrating the coastdown equation using the measured wind and other ambient conditions to generate a simulated coastdown. This is compared to the measured speed data in a least squares error sense.

$F(\mathbf{x})=\sum_{i=1}^{m}\left[f_{i}(\mathbf{x})\right]^{2}=\sum_{i=1}^{m}\left[v_{m_{i}}-v_{i}(\mathbf{x})\right]^{2}$

By varying the values of the coefficients in the vector $\mathbf{x}$, the optimisation routine converges to a minimum of the cost to give the best estimate of the coefficients. This method of extracting the coefficients directly from the measured speed data avoids the need to differentiate measured data. The data is normally sampled at $5 \mathrm{~Hz}$, but the cost is calculated using overlapping bands of duration 3 seconds. This has the effect of reducing the influence of measurement noise.

\section{RESULTS AND DISCUSSION}

The coastdown tests were conducted twice for all configurations in two series of tests, carried out by different operators (one pair from Loughborough University and a different pair from Rover Group), and separated in time by almost a year. The drag coefficients derived from these tests are compared with wind tunnel data obtained from the MIRA full scale wind tunnel in Figure 4 and Table 3.

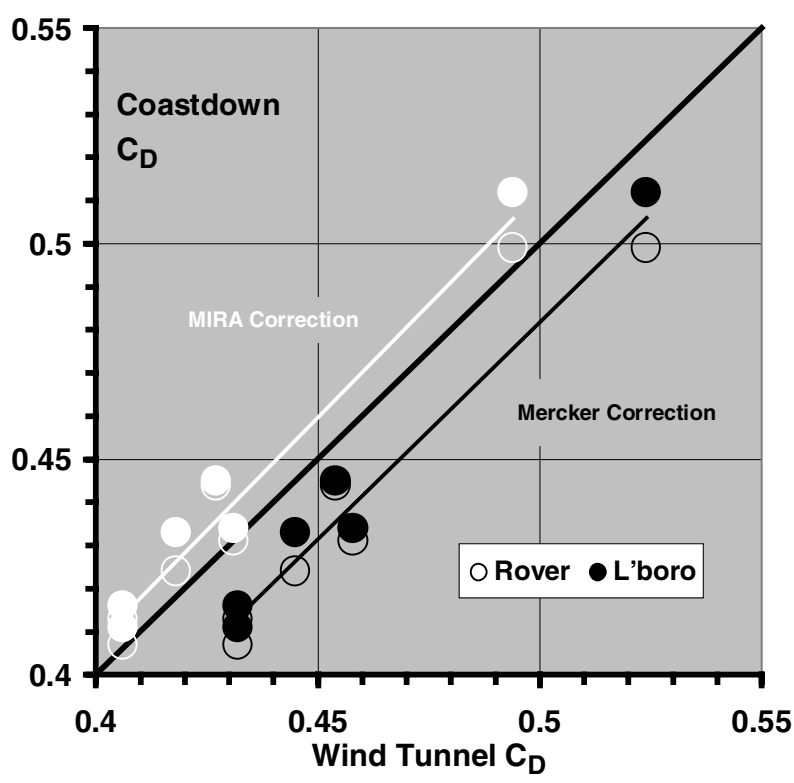

Figure 4. Coastdown drag compared with MIRA wind tunnel data. Configurations $1-5.0^{\circ}$ Yaw angle. 
Licensed from the SAE Digital Library Copytght 2010 SAE International

Copyright $\odot 2002$ SAE International. This paper-is posted on this site withpermission from SAE International, and is for viewing only. Further distribution and use of this paper is not permitted withoul permission from SAE.

\begin{tabular}{|c|c|c|c|c|}
\cline { 2 - 5 } \multicolumn{1}{c|}{} & \multicolumn{4}{c|}{$\mathrm{C}_{\mathrm{D}} 0^{\circ}$ Yaw } \\
\cline { 2 - 5 } & \multicolumn{2}{c|}{ Coastdown } & \multicolumn{2}{c|}{ MIRA Wind Tunnel } \\
\hline Config. & Rover & L'boro & Std corr & Mercker \\
\hline 1 & 0.413 & 0.411 & 0.406 & 0.432 \\
\hline 2 & 0.499 & 0.512 & 0.494 & 0.524 \\
\hline 3 & 0.444 & 0.445 & 0.427 & 0.454 \\
\hline 4 & 0.431 & 0.434 & 0.431 & 0.458 \\
\hline 5 & 0.424 & 0.433 & 0.418 & 0.445 \\
\hline 1 & 0.407 & 0.416 & 0.406 & 0.432 \\
\hline
\end{tabular}

Table 3. MIRA Wind Tunnel data compared with coastdown data.

The open and solid symbols, refer to tests carried out by Rover and Loughborough respectively. The first set of results were consistently lower than the second, with a mean difference of -0.006 in drag coefficient. Only in the highest drag configuration does the absolute difference exceed 0.01 . The cause of this systematic difference is not fully understood but is thought to be associated with the anemometer calibration method. The baseline 3-door hardtop configuration was also tested twice, as an initial and final test configuration, in both sets of tests. The drag coefficients from these four coastdown tests range from 0.407 to 0.416 . This spread of data and the small differences between the two sets of results is a measure of the robustness of the technique.

The wind tunnel data is corrected using two different techniques. In the standard MIRA blockage correction, which is based on flow continuity, the only parameter is the ratio of vehicle frontal area to working section area. This gives drag coefficients which are consistently lower than those measured in the coastdown tests. The volume based correction method derived by Mercker (11) is considered to be more representative of the physics involved, and always gives lower correction values than the MIRA standard method, resulting in higher drag coefficients. With this correction the wind tunnel data is consistently higher than the track derived measurements. The difference in drag coefficient between the two correction methods is between 0.026 and 0.030 . For both correction methods the slopes of the mean lines comparing tunnel and coastdown data are almost identical.

A similar comparison between the MIRA wind tunnel and road derived drag data for a saloon car, Le Good et.al (1) also found that the coastdown data fell between wind tunnel data corrected by the two different methods, as used here. It would be simple to conclude that a better correction method would lie somewhere between the two techniques. Unfortunately this does not take into account the poor simulation of the relative ground motion between car and road, the lack of wheel rotation, and the ground plane boundary layer growth in the conventional wind tunnel test. Aerodynamic drag measurements derived from the coastdown test include a windage loss from the wheel rotation. These are clearly not present in the case of fixed ground tests, and even some moving belt configurations do not provide a direct measure of the total resistance arising from rotating wheels.

In these tests shape changes were confined to the upper body surfaces. Earlier results by Le Good et al. (1) have shown that, under these circumstances, incremental drag coefficients obtained from coastdown testing tend to agree with wind tunnel measurements. When changes are made to the underfloor or to the front spoiler, however, differences can arise.

It is interesting to note that the variation in drag coefficient arising from alternative correction methods exceeds the variation from on-road measurements. A similar comment can be made regarding the variation in drag measurements from different wind tunnels, as found from correlation studies conducted with a range of vehicle types using most of the European automotive wind tunnels, as reported by Mercker and Wiedemann (12), and Wickern (13). These tests were carried out by members of the EADE group, representing the Aerodynamics departments of most European manufacturers. The variation in drag coefficient between wind tunnels can exceed 0.020 . Both papers suggested correction methods to reduce the variability.

There is considerable variation between different automotive wind tunnels and from alternative correction methods. The coastdown technique for measuring drag coefficients on-road may be used to improve correction methods for specific facilities, and, by implication, reduce the variation between different facilities. Some of the uncertainty that exists regarding which wind tunnel is correct can be reduced, but not fully resolved, by comparison with on-road drag data. This was proposed by Walter et al (6), but was also implicit in the earlier studies by Le Good et al (1). Similarly, alternative ground simulation methods may also be validated by comparison with coastdown derived data.

In contrast with the data presented here, coastdown drag measurements reported by Walter et al (6) were found to be consistently lower than those obtained in the Lockheed wind tunnel. The tunnel data was corrected using both continuity and pressure signature methods. In this study comparability between MIRA and Lockheed wind tunnels was assumed based on correlation studies carried out in the early 1980's. This correlation may no longer be valid so conclusions based on it are flawed, but the suggestion that differences in the coastdown analysis methods may be significant is valid.

The principal features of this analysis which differ from reference (6) are given below.

(a) A simple representation of the variation of drag with yaw, as shown in equation 3 , is used. 
(b) The data is filtered during data acquisition, but no data rejection algorithm or subsequent smoothing of the data is applied, other than to calculate the cost function using overlapping 3 second data segments.

(c) Tyre drag is represented by the simple expression, $(A+B v)$, as shown in equation 2 .

Higher order terms for items (a) and (c) were used in (6).

The current coastdown method assumes a parabolic relationship between drag and yaw angle as shown in equation 3. The constant, $\mathrm{Kd}$, is determined from the coastdown data. An example result is shown in Figure 5 for the baseline configuration, where four sets of data were obtained. The results are compared with the wind tunnel data at yaw corrected by both continuity (MIRA) and Mercker methods. Though it is clear that this representation generates the zero yaw angle drag coefficient with reasonable consistency, the values of $\mathrm{Kd}$ vary considerably, and it is not able to capture more complex variations with yaw angle, and in particular any asymmetry in the wind tunnel data. The range of yaw angles considered in the coastdown data is limited by the ambient wind conditions at the time of the test. The yaw data shown includes $90 \%$ of that obtained. The larger yaw angles are only generated at low vehicle speeds where aerodynamic loads are low and the impact on deceleration small. Accuracy of the drag data at these higher yaw angles is therefore suspect, and the useful yaw range is considerably less than that shown in Figure 5, and is, probably, only a few degrees either side of the mean. In spite of these limitations the similarity between the trends in the coastdown and wind tunnel data for drag at yaw is encouraging.

Some improvement to the coastdown technique may be possible if the drag variation with yaw as measured in the wind tunnel is prescribed, including asymmetry,

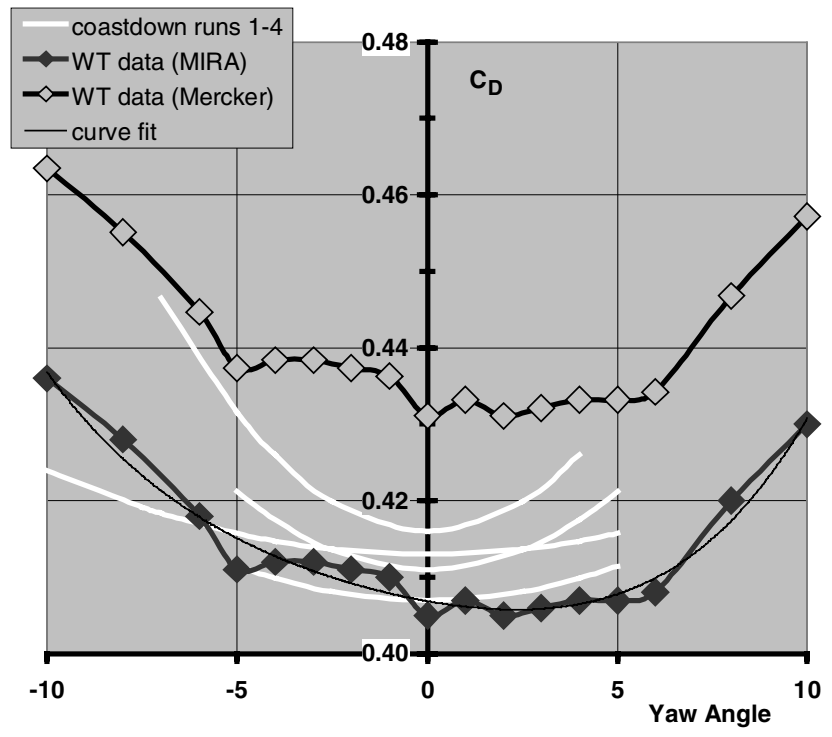

Figure 5. Comparison of drag data at yaw obtained in the wind tunnel while keeping the zero yaw drag as a variable. A $4^{\text {th }}$ order curve fit is shown in Figure 5. Figure 3, however, shows that the drag rise with yaw and the magnitude of any asymmetry varies with configuration. Initial studies involving more complex forms of the relationship between drag coefficient and yaw angle have produced highly variable results, but this investigation will be continued by performing a series of coastdown tests in various wind conditions, and by looking at the data reduction algorithms. The inclusion of data rejection techniques and digital filtering will be considered.

A comparison of the different data reduction techniques, as suggested in reference (6) would be valuable, and may be considered for future study.

\section{CONCLUSIONS}

Full scale testing of a compact SUV, in a range of configurations, have been carried out in the MIRA wind tunnel and on the MIRA test track. The conclusions apply to these specific facilities.

Drag coefficients measured on-road using the coastdown technique, by different operators at different times under different conditions, are very similar and demonstrates the robustness of the technique.

For the range of configurations tested a good correlation between the wind tunnel and on-road Aerodynamic drag data at zero yaw is established.

It is noted that for the vehicle configurations tested here, the $C_{D}$ against yaw angle characteristic is not well represented by the parabolic function generally employed in the coastdown method. The use of alternative function to represent higher order effects and asymmetry may yield benefits.

The variation in wind tunnel measurements of drag coefficient due to different commonly applied correction methods are considerably larger than the spread of drag data derived on-road.

Different wind tunnels generate a range of drag values for a given test vehicle. This variation can also be larger than the spread of drag data derived in the on-road tests reported here.

Potential differences in on-road data may arise from alternative coastdown analysis methods, but this has not been addressed.

The coastdown technique for measurement of drag coefficients on-road may be used to improve understanding of the differences between facilities, but it cannot fully resolve them. It may demonstrate the effectiveness of alternative ground simulation strategies. 


\section{NOTATION}

The authors wish to thank both Land Rover and Loughborough University for permission to publish this paper. Thanks are also extended to the operating staff of the MIRA full scale wind tunnel and Dr. Geoff Le Good (now with Bentley Motors) who was responsible for establishing the coastdown procedure within Rover Group (formerly parent group for Land Rover).

\section{REFERENCES}

1. Le Good, G.M., Howell, J.P., Passmore, M.A., Cogotti, A.. A Comparison of On-Road Aerodynamic Drag Measurements with Wind Tunnel Data from Pininfarina and MIRA. SAE Paper 980394, 1998.

2. Mercker, E., Soja, H., Wiedemann, J.. Experimental Investigation on the Influence of Various Ground Simlation Techniques on a Passenger Car. 'Vehicle Aerodynamics', R.Ae.S. Conference, Loughborough University, UK, 1994.

3. Cogotti, A.. Ground Effect Simulation for Full Scale Cars in the Pininfarina Wind Tunnel. SAE Paper 950996, 1995.

4. Buckley, F.T.. ABCD - An Improved Coast Down Test and Analysis Method. SAE Paper 950626, 1995.

5. Le Good, G.M., Howell, J.P., Passmore, M.A., Garry, K.P.. On-Road Aerodynamic Drag Measurements Compared with Wind Tunnel Data. SAE Paper 950627, 1995.

6. Walter, J.A., Pruess, D.J., Romberg, G.F.. Coastdown/Wind Tunnel Drag Correlation and Uncertainty Analysis. SAE Paper 2001-01-0630, 2001.

7. Buckley, F.T., Marks, C.H., Walston, W.H.. Analysis of Coast-Down Data to Assess Aerodynamic Drag Reduction on Full-Scale Tractor-Trailer Trucks in Windy Environments. SAE Paper 760850, 1976.

8. Eaker, G.W.. Wind Tunnel-to-Road Aerodynamic Drag Correlation. SAE Paper 880250, 1988.

9. Passmore, M.A., Le Good, G.M.. A Detailed Drag Study using the Coastdown Method. SAE Paper 940420, 1994.

10. Road Load Measurement Using On-Board Anemometry and Coastdown Techniques. SAE Recommended Practice J2263, October 1996.

11. Mercker, E.. A Blockage Correction for Automotive Testing in a Closed Wind Tunnel. $6^{\text {th }}$ Colloquium on Industrial Aerodynamics. Aachen, June 1985.

12. Mercker, E., Wiedemann, J.. On the Correction of Interference Effects in Open Jet Wind Tunnels. SAE Paper 960671, 1996.

13. Wickern, G.. On the Application of Classical Wind Tunnel Corrections for Automotive Bodies. SAE Paper 2001-01-0633, 2001.

$\begin{array}{ll}A_{A} & \text { Vehicle frontal area } \\ A_{d} & \text { Tyre rolling resistance coefficient } \\ A_{t} & \text { transmission loss coefficient } \\ B_{d} & \text { Speed dependent tyre rolling resistance coefft } \\ B_{t} & \text { transmission loss coefficient } \\ C_{D} & \text { aerodynamic drag coefficient } \\ C_{D o} & \text { aerodynamic drag coefficient at zero yaw } \\ C_{L F} & \text { aerodynamic lift coefficient, front axle } \\ C_{L R} & \text { aerodynamic lift coefficient, rear axle } \\ C_{t} & \text { transmission loss coefficient } \\ D_{t} & \text { transmission loss coefficient } \\ F_{D} & \text { resistive force } \\ F_{M} & \text { mechanical losses } \\ F_{T} & \text { tractive effort } \\ G & \text { gravitational acceleration } \\ K_{T} & \text { tyre temperature correction coefficient } \\ M & \text { Vehicle mass } \\ M_{e} & \text { Total effective mass } \\ T_{0} & \text { Observed ambient temperature } \\ T_{\text {oil }} & \text { Driveline oil temperature } \\ T_{S} & \text { Standard ambient temperature } \\ t & \text { time } \\ V & \text { velocity } \\ V_{r} & \text { airspeed } \\ \alpha & \text { track inclination } \\ \rho & \text { air density } \\ \psi & \text { yaw angle }\end{array}$

\section{CONTACT}

Jeff Howell

Manager, Aerodynamics

Land Rover

jhowel17@landrover.com

Chris Sherwin

Principal Engineer, Aerodynamics -Large 4x4

Land Rover

csherwi1@landrover.com

Martin Passmore

Senior Lecturer,

Department of Aeronautical and Automotive Engineering

Loughborough University

m.a.passmore@lboro.ac.uk

Geoff Le Good

Manager, Aerodynamics

Bentley Motors

geoff.legood@ bentley.co.uk 